\title{
The Study on the Comprehensive Assessment Management for the Mid-Term Screening of Postgraduate Students
}

\author{
Weiwei Li \\ College of Information \\ Qilu University of Technology \\ Shandong Academy of Sciences \\ Jinan, China \\ lww@qlu.edu.cn
}

\author{
Weiyang Chen * \\ College of Information \\ Qilu University of Technology \\ Shandong Academy of Sciences \\ Jinan, China \\ chenweiyang@qlu.edu.cn
}

\begin{abstract}
Education management of graduate students is very important in education. It is an important task to cultivate students with high quality, strong scientific research ability, strong practical ability and suitable for social development needs. Mid-term screening is a very important part of graduate training. By putting a computer in the field of rough set theory is introduced into the analysis of mid-term screening in the process of comprehensive evaluation index, through attribute reduction algorithm to analyze many indicators, indicates that the key factors affecting mid-term screening of comprehensive assessment. In view of these key factors, the corresponding measures are formulated to effectively guide the graduate training process, thus cultivating excellent talents for the country.
\end{abstract}

Keywords-Education management of graduate students; Midterm screening; Rough set theory; Attribute reduction algorithm

\section{INTRODUCTION}

With the continuous development of the society, the development of university education level increasing, the number of graduate students in China have also been increased, the resulting the cultivation of graduate students has become a very important problem [1]. Currently, each college graduate cultivation units have developed detailed link and process, mainly includes: the graduate student's teaching, literature reading, literature reading assessment, opening report, medium-term screening of comprehensive appraisal, mid-term paper checks until graduation reply. In these links, the midterm screening comprehensive assessment plays an important role in the future. Mid by screening the indicators in the comprehensive evaluation analysis, such as: learning achievement evaluation, ideological and political performance appraisal and assessment of scientific research ability, etc., draw relevant conclusions, on the one hand, to encourage outstanding graduate student, give scholarship issue; On the other hand, I actively guide the graduate students with poor research ability and learning ability, so as to achieve the final successful graduation through the promotion of personal ability[2].

Screening in order to improve the graduate students in the middle of the analysis of the comprehensive evaluation index

Natural Science Foundation of Shandong Province, China (ZR2017BF041). precision, we put forward the rough set theory is applied to the analysis in the field of computer, through the analysis tool, we the candidate screening of comprehensive appraisal index data are detailed analyses, classifying the postgraduate students, such as: whether the outstanding students. Therefore, it is effective to find out the important indexes that affect the comprehensive assessment of mid-term screening of postgraduate students [3]. We aimed at specific indicators formulate corresponding measures, to efficiently guide graduate students the second half of the limit of study, provide a favorable basis for the cultivation of graduate students in colleges and universities, effectively guarantee the candidate screening link after the training work smoothly [4].

\section{RELEVANT THEORETICAL BASIS}

Rough Set (also known as Rough Set, Rough Set, abbreviated as RS) is a polish mathematician Z.P awlak rules for the development of the automatic generation system and the research of soft computing problem in 1982 a mathematical theory of analysis data, incomplete and uncertainty of the new mathematical tools, the initial research on Rough Set theory are mostly published in polish, so did not cause the attention of the international computer science and math, study area is limited in some countries in eastern Europe. It was not until the late $1980 \mathrm{~s}$ to attract the attention of scholars. In the early $1990 \mathrm{~s}$, people gradually realize the importance of it [5].

The inaccuracy is the key word of rough set theory, which involves many substantive contents in the definition of set theory. The approximate definition of collection is one of the important concepts in modern mathematics, and the classical set theory which is very relevant to Boolean logic is the core of mathematics computer operation. However, the rough set theory can effectively analyze and deal with incomplete information such as imprecise, inconsistent and incomplete information, and discover implicit knowledge from it to reveal the underlying law [6].

One of the characteristics of rough set theory is that no prior knowledge is required. The commonly used method dealing with uncertain information, these methods need some additional information or prior knowledge of data, such as 
Fuzzy membership function and probability distribution, sometimes it's not easy to get these information. The analytical method of rough set theory can only use the information provided by the data itself without any prior knowledge [7].

Rough set is a soft computing method. The concept of Soft Computing is proposed by Zadeh, founder of the fuzzy set. The main tools in the soft computing including Rough Set, Rough Set, Fuzzy Logic (Fuzzy Logic), neural Network (Nerve Network), probabilistic Reasoning (aim-listed Probability Reasoning), the reliability Network (are Network), genetic algorithm (GA) with other evolutionary optimization algorithm, and the theory of Chaos (Chaos) [8]. The traditional calculation method is called Hard Computing, which USES precise, fixed and invariant algorithms to express and solve problems. And allowed the guiding principle of the soft computing is the use of the imprecision, uncertainty and part of the authenticity for easy to handle, strong robustness and lower cost solution, in order to better coordinate with reality system.

Rough set in the medical diagnosis, meteorology, telecommunications, banking and finance industry, market research, machine learning, knowledge discovery and decision support, process control, pattern recognition and analysis, inductive reasoning, expert system, data mining and many other fields has been widely used [9].

The uncertainty of rough set theory is based on the concept of upper and lower approximation [10].

Definition 1: By equivalence, $\mathrm{R}$ is not classified on $\mathrm{X}$ and cannot be classified on $\sim \mathrm{X}$. If $\mathrm{BN}_{\mathrm{R}}(\mathrm{X})$ is an empty set, then the set $\mathrm{X}$ is clear about R; Whereas the set $\mathrm{X}$ is Rough (R-Rough), the set $\mathrm{X}$ is the Rough set of $\mathrm{R}$.

Definition 2: The decision table $\mathrm{S}=(\mathrm{U}, \mathrm{C} \cup \mathrm{D}), \mathrm{R} \subseteq \mathrm{C}$, called $\mathrm{R}$ is a $\mathrm{D}$ of $\mathrm{C}$ and only if $\mathrm{R}$ is a separate subset of $\mathrm{C}$, and $\mathrm{POS}_{R}(\mathrm{D})=\mathrm{POS}_{\mathrm{C}}(\mathrm{D})$, The $\mathrm{D}$ of $\mathrm{C}$ is Relative Reduction, hereinafter referred to as Reduction (Reduction), remember to Red (C).

Definition 3: Assuming that $\mathrm{dx}$ is a get rid of all the surplus condition attributes values of decision rules, the condition attribute set of equivalence class $[\mathrm{X}] \mathrm{c}$ any minimum attribute a equivalence class in $[\mathrm{X}] \mathrm{C}$ as to the intersection of corresponding decision class, is therefore to get the minimum condition attributes of a new decision rules of the corresponding to $\mathrm{dx} \mathrm{dx}$ 'is a decision rule reduction of $\mathrm{dx}$.

Definition 4: The decision table $S=(U, C \cup D)$, The set of all irreducible attributes of $\mathrm{C}$ is called the Core of $\mathrm{C}$. Note as Core(C).It's all about the compact of $\mathrm{C}$. that is Core $(\mathrm{C})=$ $\cap \operatorname{Red}(\mathrm{C})$.

Definition 5: Assume that $\mathrm{P} \rightarrow \mathrm{Q}$ is a decision rule on the decision table, the attribute value $\mathrm{V}$ is one that can be reduced if and only if( $\rightarrow$ Q $) \rightarrow(\mathrm{P}-\{(\mathrm{A}, \mathrm{V})\} \rightarrow \mathrm{Q})$, Where $\mathrm{P}$ and $\mathrm{Q}$ are logical formulas on the decision table.

Analysis of the comprehensive assessment management for the mid-term screening of graduate students

By randomly selecting 30 graduate students in a university as the analysis of the data sample, collect their name, gender, enrollment, whether to outstanding students, ideological and political performance appraisal situation, the study result of the situation, the scientific research ability, and screening of comprehensive evaluation in the middle of the last. As shown in TABLE 1. Fig.1 shows the flow chart of graduate data samples using the rough set attribute reduction algorithm.

Analyze data by using rough set theory in computer field. Firstly, the decision table is established, the data in the decision table is discretized and the decision table of digital representation is generated. Second, by attribute reduction algorithm of rough set theory to digital attribute reduction of decision table, after removing the duplicate rows attribute, the simplified decision-making table was got after attribute reduction. Again, the attribute value of the newly generated decision table is reduced, and a more simplified and accurate decision table is obtained. Finally, by the resulting decision table we can see out excellent students and ideological and political performance appraisal outstanding, excellent academic record outstanding, scientific research ability of examination, then the screening of comprehensive evaluation for good in the medium term; Regardless of whether gender is male or female, as long as it is past life, mid-term screening comprehensive assessment is "qualified"; Regardless of the gender is male or female, as long as the ideological and political performance assessment, assessment, scientific research ability assessment of the three grades as long as there is a bright "yellow card", then "yellow card" mid-term screening of comprehensive appraisal to shine. For the results of analysis, we can see that the mid-term screening results of excellent students are better, and the mid-term screening results of fresh graduates are better, and the mid-term screening results of previous students are not very good. In management for the future, we should formulate corresponding policies and targeted past life and learning of the bright students "yellow card" strict management, in order to successfully complete their studies, get good grades.

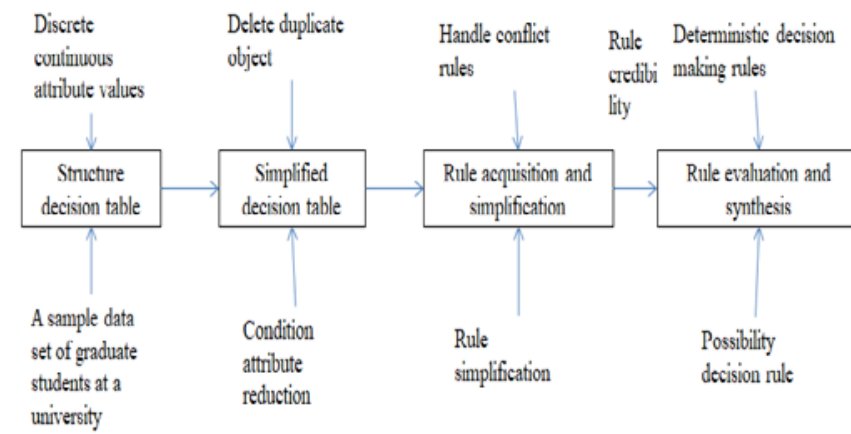

Get the key elements

Fig. 1. An attribute reduction algorithm based on rough sets is used to analyze the flow chart of graduate data samples. 
TABLE I. RANDOM SAMPLING OF 30 GRADUATE ST UDENTS

\begin{tabular}{|c|c|c|c|c|c|c|c|c|}
\hline Number & Name & Gender & Enrollment & $\begin{array}{c}\text { Whether to } \\
\text { outstanding } \\
\text { students } \\
\end{array}$ & $\begin{array}{l}\text { Ideological and political } \\
\text { performance appraisal } \\
\text { situation }\end{array}$ & $\begin{array}{l}\text { The study result } \\
\text { of the situation }\end{array}$ & $\begin{array}{l}\text { The scientific } \\
\text { research ability }\end{array}$ & $\begin{array}{c}\text { Screening of comprehensive } \\
\text { evaluation in the middle of the } \\
\text { last }\end{array}$ \\
\hline 1 & $\mathrm{~A}$ & man & new student & yes & excellent & excellent & excellent & excellent \\
\hline 2 & B & man & $\begin{array}{c}\text { former } \\
\text { student }\end{array}$ & no & excellent & qualified & qualified & qualified \\
\hline 3 & $\mathrm{C}$ & female & $\begin{array}{c}\text { former } \\
\text { student }\end{array}$ & no & qualified & qualified & qualified & qualified \\
\hline 4 & $\mathrm{D}$ & female & $\begin{array}{l}\text { former } \\
\text { student }\end{array}$ & no & qualified & qualified & qualified & qualified \\
\hline 5 & $\mathrm{E}$ & man & new student & yes & qualified & qualified & qualified & qualified \\
\hline 6 & $\mathrm{~F}$ & man & new student & yes & qualified & qualified & qualified & qualified \\
\hline 7 & $\mathrm{G}$ & female & new student & yes & qualified & qualified & qualified & qualified \\
\hline 8 & $\mathrm{H}$ & female & new student & yes & qualified & qualified & qualified & qualified \\
\hline 9 & $\mathrm{I}$ & man & new student & yes & excellent & excellent & excellent & excellent \\
\hline 10 & $\mathrm{~J}$ & man & $\begin{array}{c}\text { former } \\
\text { student }\end{array}$ & no & excellent & qualified & qualified & qualified \\
\hline 11 & $\mathrm{~K}$ & female & $\begin{array}{c}\text { former } \\
\text { student }\end{array}$ & no & qualified & excellent & qualified & qualified \\
\hline 12 & $\mathrm{~L}$ & man & $\begin{array}{c}\text { former } \\
\text { student }\end{array}$ & no & qualified & qualified & qualified & qualified \\
\hline 13 & M & $\operatorname{man}$ & $\begin{array}{c}\text { former } \\
\text { student }\end{array}$ & no & qualified & excellent & qualified & qualified \\
\hline 14 & $\mathrm{~N}$ & female & new student & yes & qualified & qualified & qualified & qualified \\
\hline 15 & $\mathrm{O}$ & man & $\begin{array}{c}\text { former } \\
\text { student }\end{array}$ & no & qualified & qualified & qualified & qualified \\
\hline 16 & $\mathrm{P}$ & female & new student & yes & qualified & qualified & qualified & qualified \\
\hline 17 & Q & man & $\begin{array}{c}\text { former } \\
\text { student }\end{array}$ & no & qualified & qualified & qualified & qualified \\
\hline 18 & $\mathrm{R}$ & man & new student & yes & excellent & excellent & excellent & excellent \\
\hline 19 & $\mathrm{~S}$ & $\operatorname{man}$ & new student & yes & excellent & excellent & excellent & excellent \\
\hline 20 & $\mathrm{~T}$ & man & new student & yes & qualified & $\begin{array}{l}\text { bright "yellow } \\
\text { card" }\end{array}$ & qualified & $\begin{array}{l}\text { bright "yellow } \\
\text { card" }\end{array}$ \\
\hline 21 & $\mathrm{U}$ & man & new student & no & qualified & qualified & qualified & qualified \\
\hline 22 & $\mathrm{~V}$ & man & new student & no & qualified & qualified & qualified & qualified \\
\hline 23 & $\mathrm{~W}$ & female & new student & no & qualified & qualified & qualified & qualified \\
\hline 24 & $\mathrm{X}$ & female & new student & no & qualified & qualified & qualified & qualified \\
\hline 25 & $\mathrm{Y}$ & man & new student & no & qualified & qualified & qualified & qualified \\
\hline 26 & $\mathrm{Z}$ & man & new student & no & qualified & qualified & qualified & qualified \\
\hline 27 & A1 & man & new student & no & qualified & qualified & qualified & qualified \\
\hline 28 & B1 & man & new student & no & qualified & $\begin{array}{l}\text { bright "yellow } \\
\text { card" }\end{array}$ & qualified & $\begin{array}{l}\text { bright "yellow } \\
\text { card" }\end{array}$ \\
\hline 29 & $\mathrm{C} 1$ & female & new student & no & qualified & qualified & qualified & qualified \\
\hline 30 & D1 & $\operatorname{man}$ & new student & no & qualified & qualified & qualified & qualified \\
\hline
\end{tabular}

Through the analysis of the graduate student's mid-term screening index, affecting the graduate student's mid-term screening, a comprehensive assessment of the key factors for this the best way to develop graduate students teaching management, to the middle screening effective guidance later stage of learning, to raise the level of our graduate students teaching, management, training, in order to raise the high quality for the state and society of outstanding graduate students.

\section{SUMMARY}

In the graduate student education management, introduces relevant knowledge in the field of computer, such as rough set theory, the application of modern technology methods in the process of the education management train of thought, also gradually become one of the methods of education management reform. Rough set theory has been widely used in the fields of finance, medicine, agriculture, human resource management, etc., and has proved to be a very effective tool. Can take advantage of this tool, we will be involved in the graduate student education management mid-term screening of comprehensive evaluation index to classify, effectively to analyze the status of the graduate students, so as to develop in line with the specific link of graduate education in colleges and universities policy, effectively to education management for graduate students, truly achieve "graduate student centered, guided by social needs" new concept of graduate student training, and education to the graduate admissions management idea and other aspects such as the graduate student employment, improve the quality of the university graduate education management.

\section{ACKNOWLEDGMENT}

This work was supported by Natural Science Foundation of Shandong Province, China (ZR2017BF041) and Graduate Tutor Mentoring Ability Enhancement Project of Qilu University of Technology (Shandong Academy of Sciences). 


\section{REFERENCES}

[1] Qidi Wu. Developing Graduate Education; Strengthening Our Country by Cultivating High- Quality Personnel, Academic Degrees \& Graduate Education, 2005 (1).

[2] Shuang Ying, Jun Kang, Zhen Liang, Xuemei Ding. Exploration and Practice: Innovation of the Postgraduate Training Model in China, Journal of Graduate Education, 2014, (1).

[3] Gang Wang, Yimei Cui, Jiancheng Chen. Study on graduate education pattern in the new situation, Science-Technology and Managements, vol.10, pp. 112-115, 2008.

[4] Lei Gao, Wenhua Zhao. Characteristics, Motivation and Models of Interdisciplinary Training for Graduate Students, Journal of Graduate Education, 2014, (03), pp. 32-36.

[5] S Greco, B Matarazzo, R Słowiński. On Topological Dominance-based Rough Set Approach[J].Springer-Verlag, 2010, pp.21-45.
[6] R Słowiński, S Greco, B Matarazzo. Rough Set Methodology for Decision Aiding[J]. Springer Berlin Heidelberg, 2015, pp.349-370.

[7] Yan Wu, Wei Wan. A New Method for Evolving Artificial Neural Networks Using Genetic Algorithm. The Proceedings International Forum on Theory of Grc from Rough Set Perspective(IFTGrCRSP2006).2006, (25), pp.79-82.

[8] Lisa Fn, Minxiao Lei.Rough Set Assited Meta-Leaning Method to Select Learing lgorithms.The Proceedings International Forum on Theory of Grc from Rough Set Perspective(IFTGrCRSP2006).2006, (25), pp.83-87.

[9] Masahiro Inuiguchi, Shoji Hirano, Shusaku Tsumoto. Rough Set Theory and Granular Computing. Springer.2003, (125).

[10] Lech Polkowski, Shusaku Tsumoto, Tsau Y. Lin. Rough Set Method and Applications: New Developments in Knowledge Discovery in Information Systems. Physica-Verlag, 2000, (56): 649-681. 